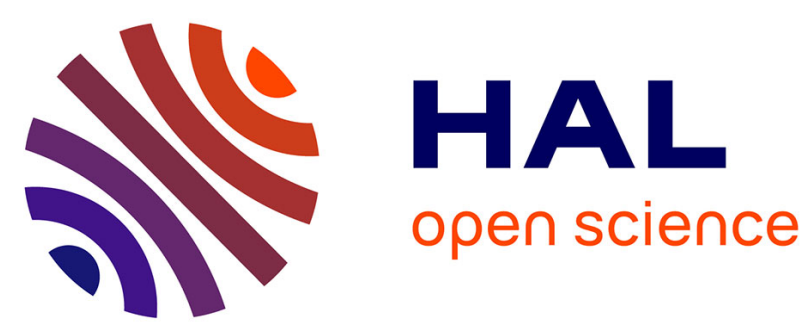

\title{
Combined use of space-borne SAR interferometric techniques and ground-based measurements on a 0.3 km2 subsidence phenomenon
}

Daniel Raucoules, Charles Cartannaz, Francis Mathieu, Dominique Midot

\section{- To cite this version:}

Daniel Raucoules, Charles Cartannaz, Francis Mathieu, Dominique Midot. Combined use of spaceborne SAR interferometric techniques and ground-based measurements on a $0.3 \mathrm{~km} 2$ subsidence phenomenon. Remote Sensing of Environment, 2013, 139, pp.331-339. 10.1016/j.rse.2013.08.016 . hal00863832

\section{HAL Id: hal-00863832 \\ https://hal.science/hal-00863832}

Submitted on 19 Sep 2013

HAL is a multi-disciplinary open access archive for the deposit and dissemination of scientific research documents, whether they are published or not. The documents may come from teaching and research institutions in France or abroad, or from public or private research centers.
L'archive ouverte pluridisciplinaire HAL, est destinée au dépôt et à la diffusion de documents scientifiques de niveau recherche, publiés ou non, émanant des établissements d'enseignement et de recherche français ou étrangers, des laboratoires publics ou privés. 


\title{
Combined use of space-borne SAR interferometric techniques and ground-based
} measurements on a $0.3 \mathrm{~km}^{2}$ subsidence phenomenon

\author{
D. Raucoules ${ }^{a *}$, C. Cartannaz ${ }^{b}$, F. Mathieu ${ }^{a}$, D. Midot $^{b}$ \\ ${ }^{a}$ BRGM, 3 avenue Guillemin, 45060, Orléans, France \\ ${ }^{b}$ BGRM Lorraine, 1 avenue du parc de Brabois, 54 500, Vandœuvre-lès-Nancy. \\ *corresponding author:d.raucoules@brgm.fr
}

Highlights:

- DInSAR is applied to a subsidence phenomenon covering a small area $\left(0.3 \mathrm{~km}^{2}\right)$.

- A combination of conventional DInSAR using L-Band data and PSI technique is proposed.

- The results were used for adapting a ground-based network to the deformation characteristics.

\section{Abstract:}

The built-up area of the village Hilsprich (Lorraine, France) is affected by a subsidence phenomenon localized over a few hundred square metres, causing damage to buildings. In this study, differential SAR interferometry (DInSAR) was used to:

- estimate the boundaries of the subsidence in order to optimize ground-based monitoring networks (levelling and geophysical measurements)

- estimate the maximum deformation and highlight the evolution of the phenomenon (previously unknown due to insufficient historical ground-based data).

The study was based both on L-band ALOS/PALSAR SAR data and C-band Envisat/ASAR data. The interest in PALSAR data lies in its better performance for InSAR with respect to C-band data on the affected non-urban areas (such as fields and farmlands) where, in addition, conventional techniques such as topographical survey information was limited, and had often not been carried out before the first damage was observed. Conventional DInSAR based on PALSAR data processing for the 2008-2010 period identified the boundary of the subsidence area and estimated its maximum magnitude. The PSI technique in the ASAR archive gave information regarding the beginning of the subsidence. The precision of the DInSAR results was consistent with 
the topographical data (in locations where this information was known) and therefore favours the SAR interferometric techniques in this context. Combined with the knowledge of the regional geological and structural setting, together with results from ground-based electrosounding, the results of the study established a basis for an increased understanding of the subsidence phenomenon, which was revealed to affect an elliptical bowl-shaped area due to salt dissolution.

Keywords: Differential SAR interferometry; salt dissolution-induced subsidence; ALOS data

\section{Introduction}

The village of Hilsprich (Lorraine, France) is affected by subsidence whose origin was unclear even in 2010 (Cartannaz, 2009), but which is now believed to be related to a salt dissolution phenomenon (Mathieu, 2011). Building damage was first observed in 2006. Survey levelling monitoring points have been installed and regularly revisited since October 2008 along the streets of the village, particularly in the vicinity of the damaged buildings.

The purpose of the present study was to provide maps of the ground surface deformation using space-borne differential interferometric synthetic aperture radar (DInSAR). The first objective was to delineate the affected area more precisely than is possible by levelling, using interferometric synthetic aperture radar (InSAR), which produces image-based results, then estimate the deformation rates as well as the date of the beginning of the phenomenon. The second objective was to optimise the distribution of the measurements by improving the levelling network and the geophysical profiles positions, in order to correctly define the whole affected area. Finally, combined with the other information, using the DInSAR results to improve our understanding of this phenomenon and its future evolution.

Two limitations to the application of InSAR lie on the characteristics of the subsidence bowl. The first limitation is related to the expected deformation rates and bowl size. The maximum deformation is more than $5 \mathrm{~cm} / \mathrm{yr}$ over a relatively small area of about $1 \mathrm{~km} \times 300 \mathrm{~m}$. Such a large deformation gradient might limit the use of large time spans (e.g. Raucoules et al., 2007), and could also reduce the effectiveness of techniques similar to persistent scatterer interferometry (PSI) that are known to underestimate high deformation rates because of temporal unwrapping issues (e.g. Raucoules et al., 2009). The second limitation is the temporal decorrelation 
phenomenon (Zebker and Villasenor, 1992) that would affect the non-urban part of the affected area. C-band data is known to be much less effective than L-band over agricultural or vegetated areas, and PSI techniques generally obtain very low persistent scatterer densities (Ferretti et al., 2003) because of the lack of long-term targets in that type of land cover.

Considering this context, the following strategy was applied:

(1) Map the deformation using data from the Advanced Land Observing Satellite phased array L-band synthetic aperture radar (ALOS/PALSAR) to establish the boundary of the subsiding bowl and estimate the maximum deformation rates. Although the precision was expected to be relatively low $(\approx 1 \mathrm{~cm} / \mathrm{yr}$, by combining small temporal baseline PALSAR interferograms) it was considered adequate for the high deformation rates in this case.

(2) Use of C-band data (Envisat ASAR) to compute a PSI times-series on persistent scatterers (PS) near the boundary of the subsidence. We therefore expected to observe small deformations for these points at the margin of the stable area, but the process would nevertheless provide information regarding the temporal evolution of the deformation.

Combining these two approaches was expected to contribute to the objectives of the study; it should be noted that the strategy was constrained by the small amount of available data for the period of interest. Had we had access to a dense archive of PALSAR images prior to 2006 (e.g. tens of images instead of a total of eight), the second approach would not have been needed: PSI based on PALSAR data would have provided the required information.

\section{SAR Interferometry methodology}

Space-borne DInSAR is widely used for obtaining ground surface deformation caused by earthquakes (e.g. Massonnet, 1993), urban subsidence due to water pumping (e.g. Raucoules et al., 2003), landslides (e.g. Delacourt et al., 2009) or mining subsidence (e.g. Perski \& Jura, 1999; Gueguen et al., 2009). Its capabilities and limitations are well known (e.g. Massonnet \& Feigl, 1998; Zebker \& Villasenor, 1992; Hanssen, 2001). The present case, however, involved partially vegetated land cover and high deformation gradients (i.e. high 

deformation rates across a small subsidence width), for which L-band data was considered to be the best choice (e.g. as discussed in Raucoules et al., 2007).

Therefore, the first approach based on L-band data was the following. After acquiring all available L-band data (PALSAR) for the test site and for the period of interest, all possible interferograms were then produced. The most reliable interferograms were selected visually, following Le Mouélic et al. (2005). The selection was based on the apparent phase noise and on the similarities between the deformation signatures on the interferograms (deformation signature is assumed to be similar for the different interferograms, whereas atmospheric effects differ). Selected interferograms were therefore unwrapped. Since the deformation signatures corresponded to less than one fringe, unwrapping errors are not likely to occur. The unwrapped interferograms were then stacked to increase the ratio between the deformation signal and the different errors (particularly atmospheric effects and unwrapping error). The result is a map of deformation rate in $\mathrm{cm} / \mathrm{yr}$. In this case, however, the small PALSAR dataset for the site (eight images, as mentioned) during the deformation period prevented us from determining the evolution of the deformation by this first approach.

Therefore, the second approach was aimed at applying PSI (e.g. Ferretti et al., 2001; Werner et al., 2003) on targets in the vicinity of the subsidence bowl, based on a series of Envisat/ASAR data. We expected that these points would be capable of reflecting the temporal evolution of the deformation but with much smaller amplitude than points located near places of maximum deformation. Noteworthy is the fact that the strong and irregular deformation rates appeared to be a limitation for standard PSI applications (Raucoules et al., 2009); therefore the proposed approach was also to take this into account. In addition, PSI techniques are generally inefficient outside urban or unvegetated areas because of the few scatterers that are stable for the whole period of data acquisition.

Both approaches were applied using GAMMA/IPTA software (GAMMA-RS ${ }^{\mathrm{TM}}$ ).

\section{Remote Sensing data}

The following sections describe the SAR data used for this study.

\subsection{ALOS PALSAR data}



preferred to produce interferograms with short temporal baselines, for the reason that we were not constrained to obtain very high precision. We anticipated high deformation rates that could be identified even with low precisions of, say, several $\mathrm{cm} / \mathrm{yr}$, but we nevertheless needed to avoid large time spans to reduce the significant temporal decorrelation effects that occur with agricultural ground cover.

We acquired two series of four PALSAR images, which was the complete single-polarisation PALSAR images set for the site. Because of the different orbits of the two tracks (series 647 and 648), it was not possible to produce interferograms between them. Our dataset allowed the production of only two series, each of six

111 interferograms. Combining interferograms from different series is only possible once the interferograms are 112 geocoded.

\subsection{Envisat data set}

117 We acquired 38 Envisat/ASAR images for the test site spanning the period from 2004 to 2009. The objective

118 was to provide information on the temporal evolution of the phenomenon, in particular its commencement in 


\begin{tabular}{ll}
\hline Year & Acquisitions dates \\
\hline 2004 & 22 Jan, 26 Feb, 1 April, 10 June, 15 Jul, 19 Aug \\
2005 & 06 Jan, 10 Feb, 21 April, 26 May, 30 June, 04 Aug, 08 Sept, 13 Oct, 17 Nov, 22 Dec \\
2006 & 26 Jan, 02 March, 11 May, 15 June, 20 Jul, 24 Aug, 28 Sept, 02 Nov, 07 Dec \\
2007 & 11 Jan, 15 Feb, 22 March, 26 April, 31 May, 05 July \\
2008 & 10 April, 02 Oct, 11 Dec \\
& 19 Feb, 04 June, 17 Sept, 26 Nov
\end{tabular}

Mean incidence angle: $23^{\circ}$

Figure 1 shows the location of the affected area. Before the present study, most of the subsidence deformation had been observed in the built-up section of the village. Figure 2 shows the three ALOS interferograms that were considered to be the more relevant for our purpose, after visual selection. The subsidence phenomenon was localized in a consistent way on the interferograms. However, some discrepancies were evident (locally up to $1 \mathrm{rad}$ ), which could have been due to atmospheric interference, as mentioned previously, but were probably also caused by variations in the soil characteristics (L-band signals are more affected than C-band by a thick upper soil layer, and the phase value is more highly influenced by variables such as humidity). Finally, the observed deformation signature was smaller by about a quarter of a fringe; we were therefore at the limit of the sensitivity of the technique based on individual interferograms. For these reasons, interferogram stacking was required to improve the result. However, although the various possible sources of detection errors were reduced, they could not be ignored since they were of the same order as the deformation signatures themselves, and interpretation based on the expected location and characteristics of the deformation (shape 
138 and simililarity between interferograms) could not be avoided. The aim of the study was not to detect new

139 deformation signatures, but to better characterise the previously observed subsidence; thus the constraints of

140 location, subsidence rates and so on made the interpretation more straightforward.

141 Line-of-sight (LOS) displacements were converted in subsidence rates from the three interferograms, assuming

142 no horizontal component of displacement. From this information, a mean deformation map was derived for

143 the period February 2008 - March 2010 (Figure 3).

144 Our assumption that horizontal deformation did not contribute to the LOS measurements invites further

145 examination. Subsidence is generally associated with horizontal displacement: for example, Tandanand and

146 Powell (1991) showed that, for coal mining subsidence, the maximum horizontal displacement is about 20-40\%

147 of the maximum vertical displacement. However:

148 (1) Even at a $38^{\circ}$ angle of incidence (ASAR data), the SAR geometry is less sensitive to the cross-track horizontal 149 component than to the vertical component. If the ratio of horizontal/vertical displacement is $30 \%$, the 150 contribution to LOS of the horizontal cross-track motion is about $23 \%$ of the vertical. An along-track 151 horizontal component does not affect the InSAR measurement.

152 (2) For a subsidence bowl, the horizontal displacement at the center of the bowl is not the maximum 153 displacement; this occurs at the inflexion points of the cross-section of the bowl. Thus the estimated maximum vertical displacement is little affected by the horizontal component of displacement.

155 The main information gained from the measurements was therefore the outline, or boundary, of the 156 subsidence area (previously unknown) and the maximum deformation rate (about $9 \mathrm{~cm} / \mathrm{yr}$ vertically). 


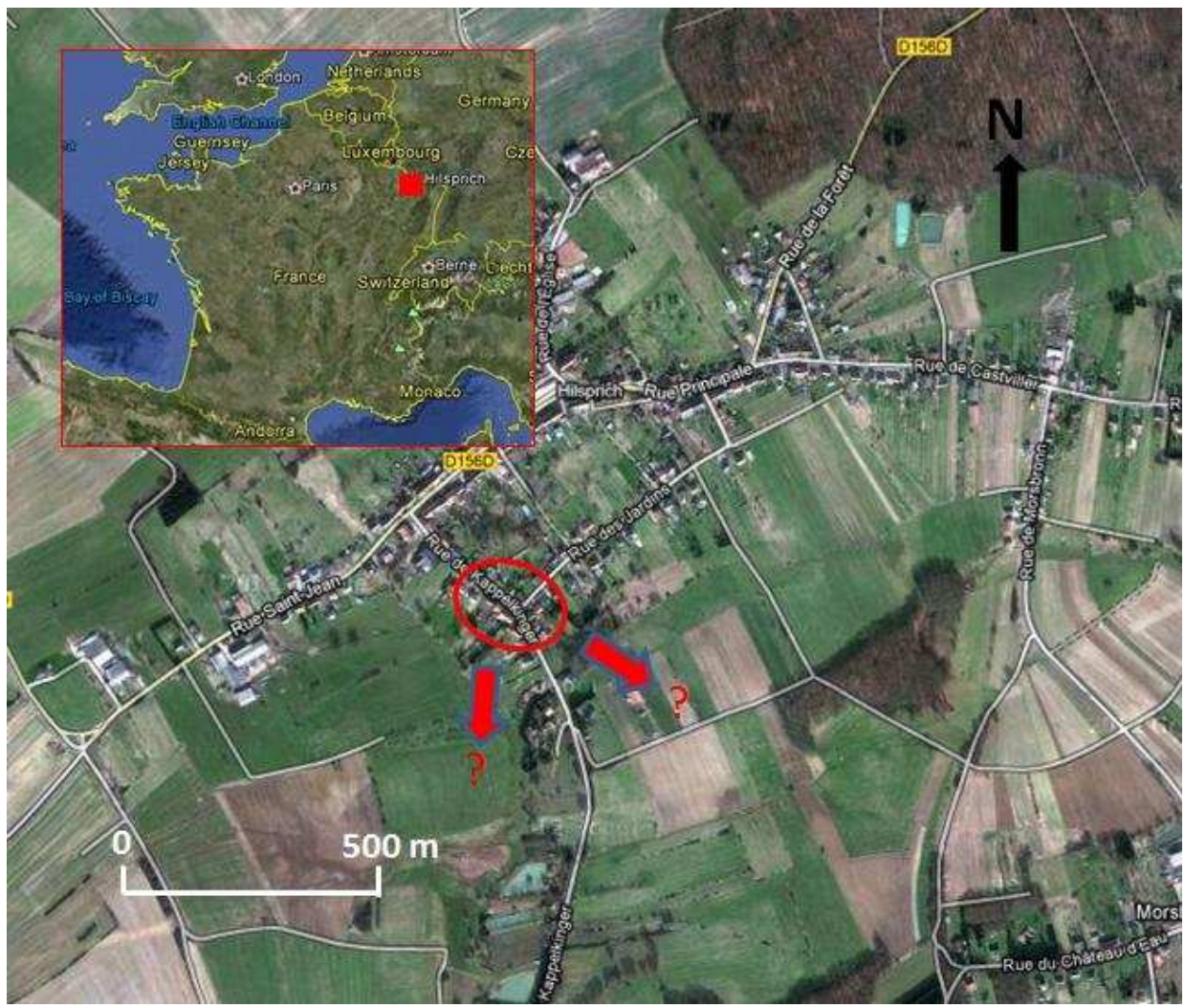

Figure 1. Location of test site. The red ellipse is the area with observed subsidence effects on buildings in 2008. One of the represented by the arrows).

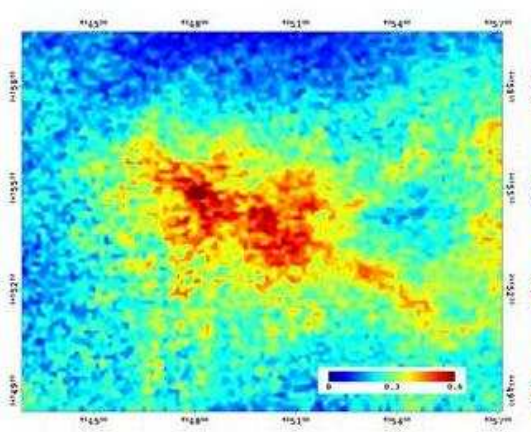

$2008 / 02 / 02-2008 / 03 / 19$

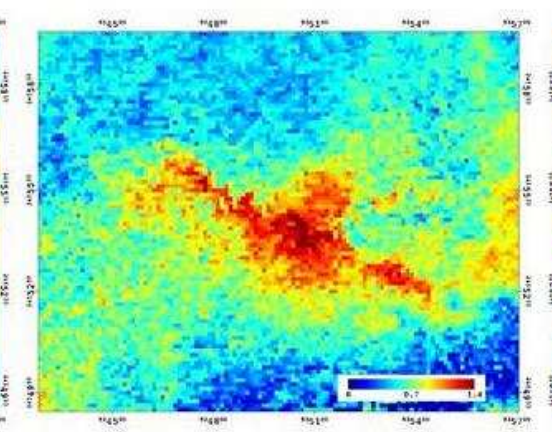

2008/01/16-2008/04/17

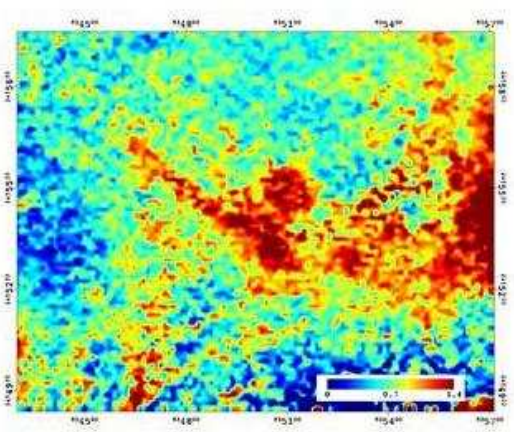

2009/12/23-2010/03/25 


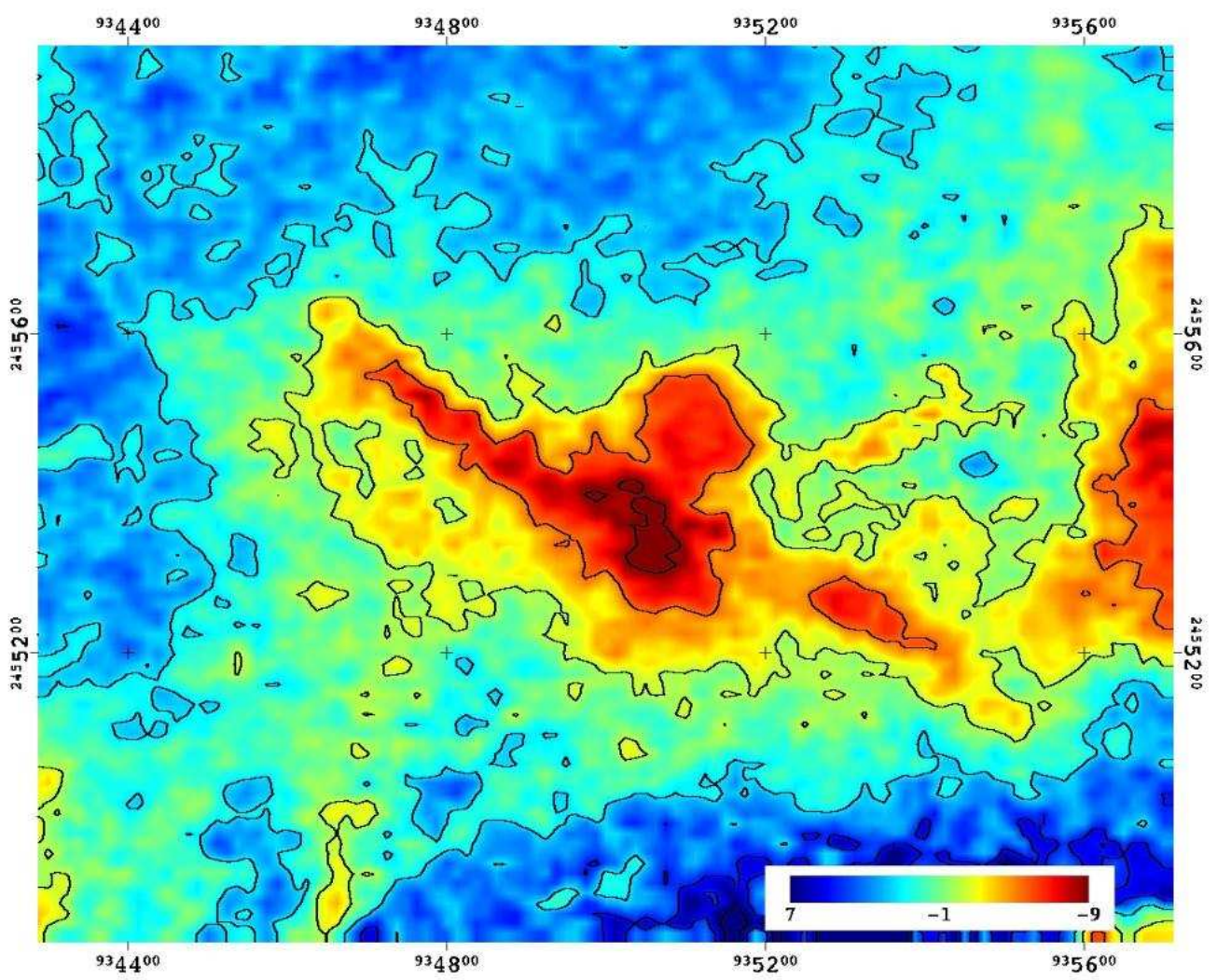

Figure 3. Stacked unwrapped interferograms from Figure 2 (values in cm/yr for line-of-sight (LOS) displacement). étendu projection (metres). For the $38^{\circ}$ incidence angle, $3 \mathrm{~cm} / \mathrm{yr}$ along LOS corresponds to $3.8 \mathrm{~cm} / \mathrm{yr}$ vertical displacement.

171 An additional observation concerns the rate variation: the comparison of two interferograms (Figure 4) shows a

172 slight apparent decrease (about 30\%) in the maximum rate of subsidence between 2008 and 2010 . This

173 observation, based as it is on a comparison between only two interferograms, does not imply with certainty that the rate was decreasing; since we were dealing with a complex phenomenon, deformation could be irregular, comprising periods of slower and faster movement. However, recently surveyed levels (2012) confirmed that the rate had decreased globally in the previous four years, as detailed in Figure 9. 


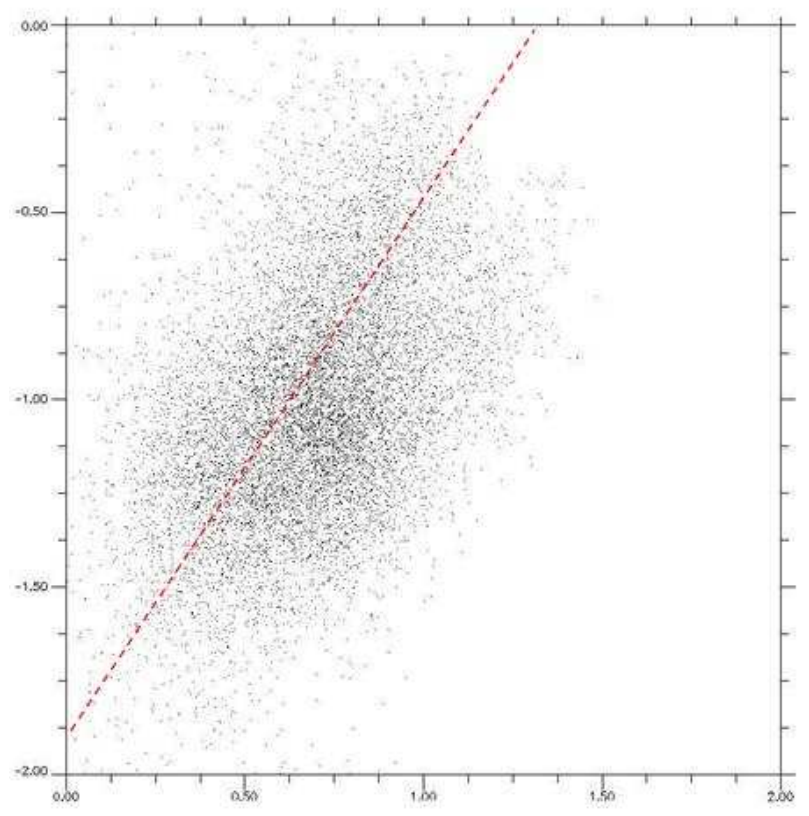

The results of PSI processing shown in Figures 5-8 represent the evolution of selected PS slightly affected by subsidence. PS close to the subsiding area, but whose time series appears stable, are not shown. PS in the area considered as the most affected by subsidence were rejected by the algorithm during processing. The two PS we considered to be the most relevant for interpretation are shown in Figure 6, which is the average. The other four time series are shown in Figure 8. Although the evolution before and after 2006 is not obvious (the ramp on the time series before 2006 was refuted by the partial PSI analysis shown in Figure 6, and is probably a consequence of phase unwrapping issues in 2008 due to the reduced amount of data for that period), the major subsidence event that occurred in 2006 is clearly seen, as corroborated by inhabitants of the town who spoke of obvious increased surface deformation and damage at that time. The observed PS moved some 1 to $1.5 \mathrm{~cm}$ between May and July 2006, a period of less than three months. centre of the bowl. 


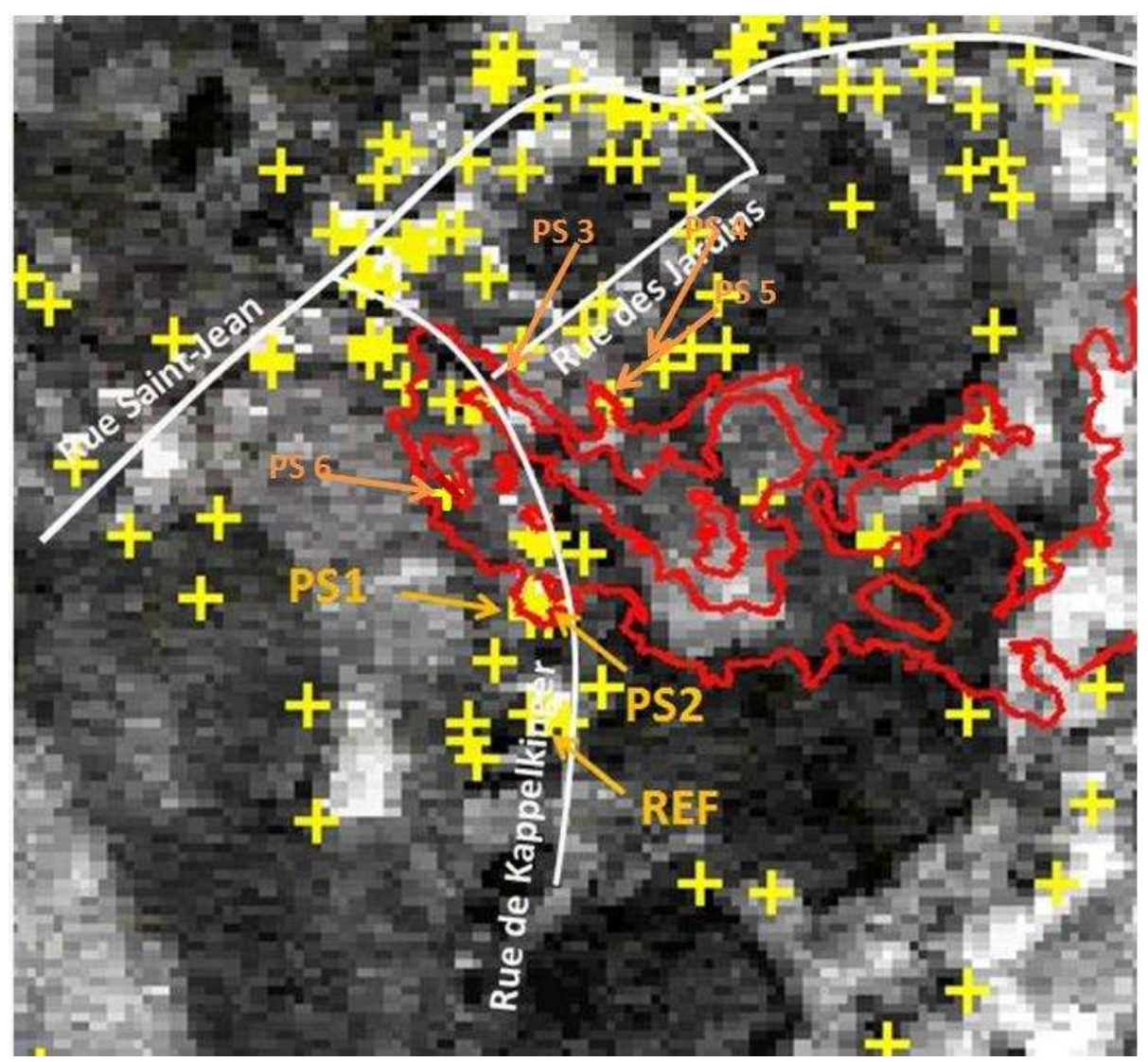



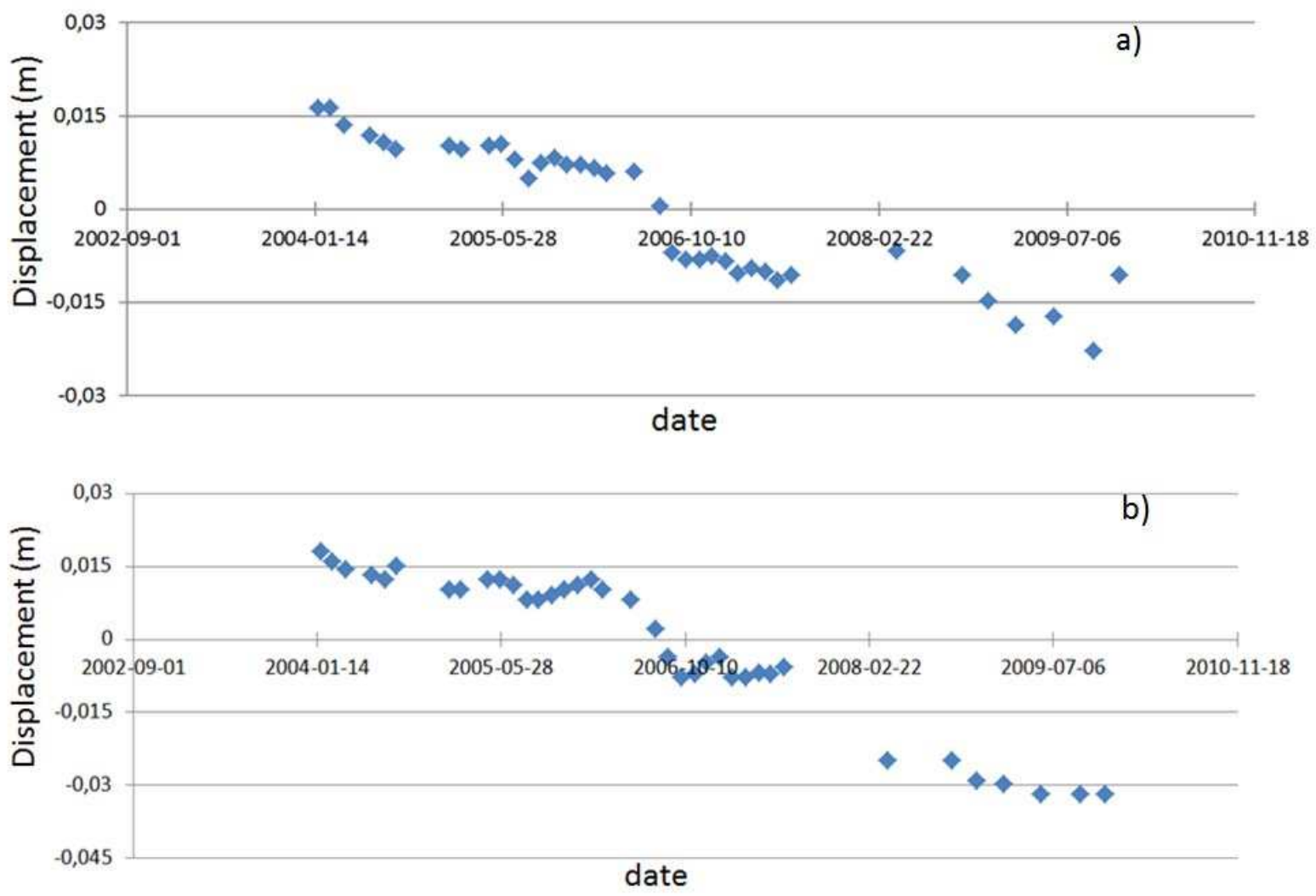

Figure 6. Time series of the PS showed in Figure 4: (a) PS1; (b) PS2. The 2006 event is clear on the time series. The trend before 2006 could be due to temporal unwrapping issues. In particular, note the lack of information for 2007 and 2008 , resulting in apparent phase jumps, and hampering the completeness of the record for this period. The mean subsidence rate derived from these time series is about $6.2 \mathrm{~mm} / \mathrm{yr}$.

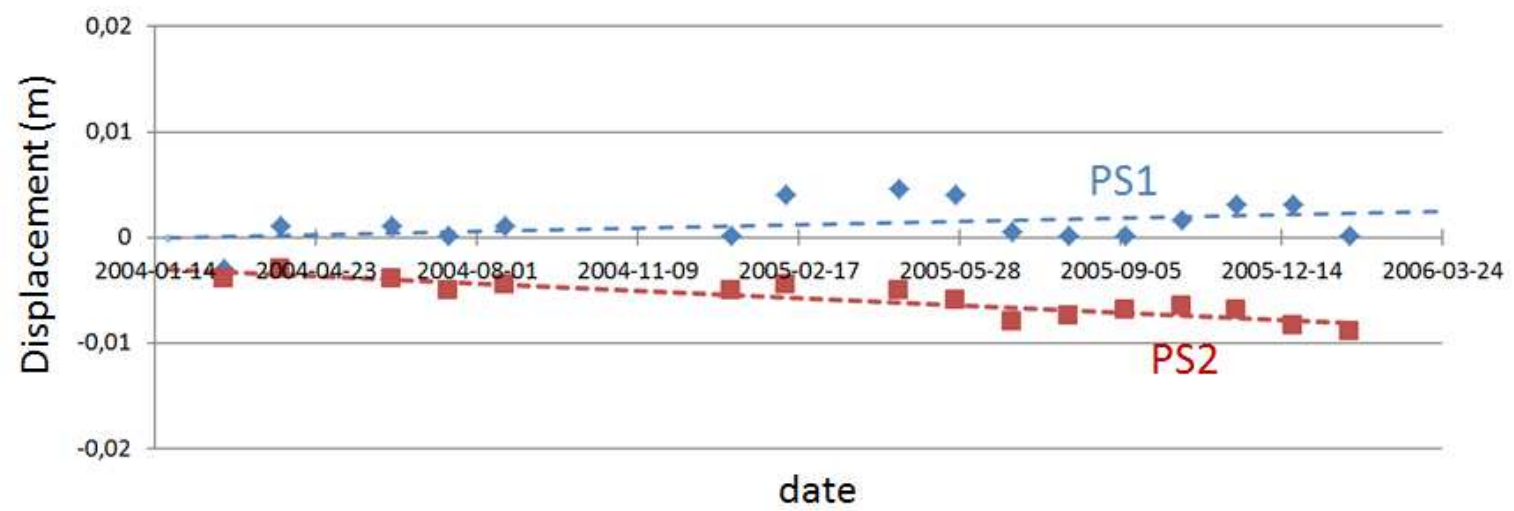




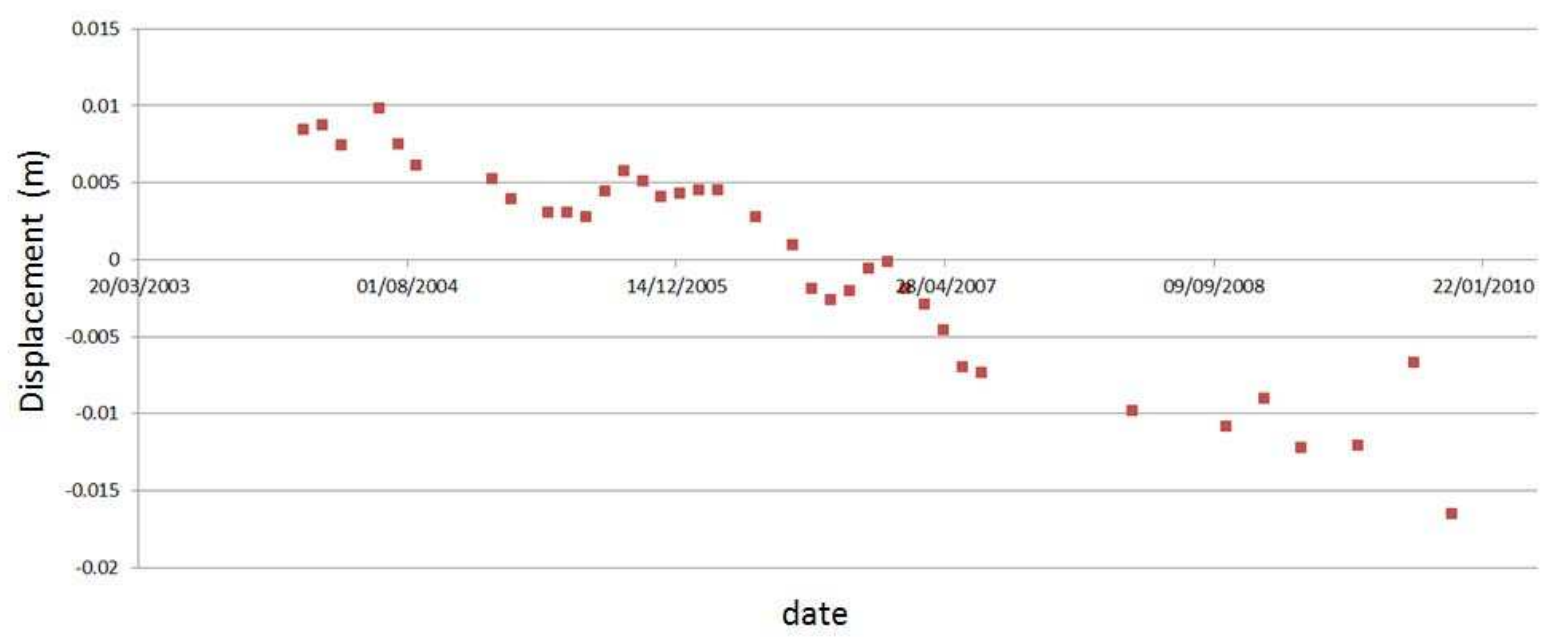

Figure 8. Average of the time series for PS 3-6. The more rapid deformation indicated for May-July 2006 was confirmed to average $7 \mathrm{~mm}$ at those four points. The overall mean rate derived from this time series is about $4 \mathrm{~mm} / \mathrm{yr}$.

\section{Optimisation of measurement and monitoring networks}

Improved mapping of the subsidence location allowed us to (1) adjust the levelling-based monitoring network, and (2) define a strategy for implementing the electrical measurement profiles (detailed in Mathieu, 2011).

Figure 9 shows the positions of points in the modified levelling network. The intention was to focus the observations on the relevant areas; note in Figure 9 the levelling points added near Brendel, which confirmed the InSAR-based observations that deformation was mainly localized south-east of the first observations (Figure 1) and pointed out a possible south-easterly acceleration and/or migration of the phenomenon. Future evolution on this area should therefore be regularly monitored. Jardins. These levelling points had been monitored since 2008 (and are different from points in the network modified in 2011). It is notable that the levelling time series possibly indicates different behaviours, and that 
the standard deviation is about $3 \mathrm{~cm} / \mathrm{yr}$ for the estimated mean value on each date. If it is confirmed that the deformation rate decreased by about $30 \%$ between 2008 and 2010, as suggested by Figure 4 , the rate fluctuated in 2008. In addition, DInSAR apparently underestimated the values at the monitored levelling points, indicating a vertical displacement rate of about $7-8 \mathrm{~cm} / \mathrm{yr}$ compared to about $11-12 \mathrm{~cm} / \mathrm{yr}$ by levelling for the same period. Several hypotheses can be combined for explaining this discrepancy: (1) The inaccuracy of the chosen reference stable area. This choice was partly arbitrary; in addition, the interferometric phase value can be influenced by local effects (e.g. atmospheric lengthening) that could alter the whole of the estimated deformation. (2) A possible smoothing effect of the filter applied to reduce the noise level, thus lowering the higher values. (3) More generally, the overall precision of surface displacement based on three interferograms spanning less than three months ( 45 to 91 days). If we assume that, at the scale of the studied area, each interferogram was affected by an imprecision of about $1 \mathrm{~cm}-\mathrm{a}$ typical value for an atmospheric phase screen

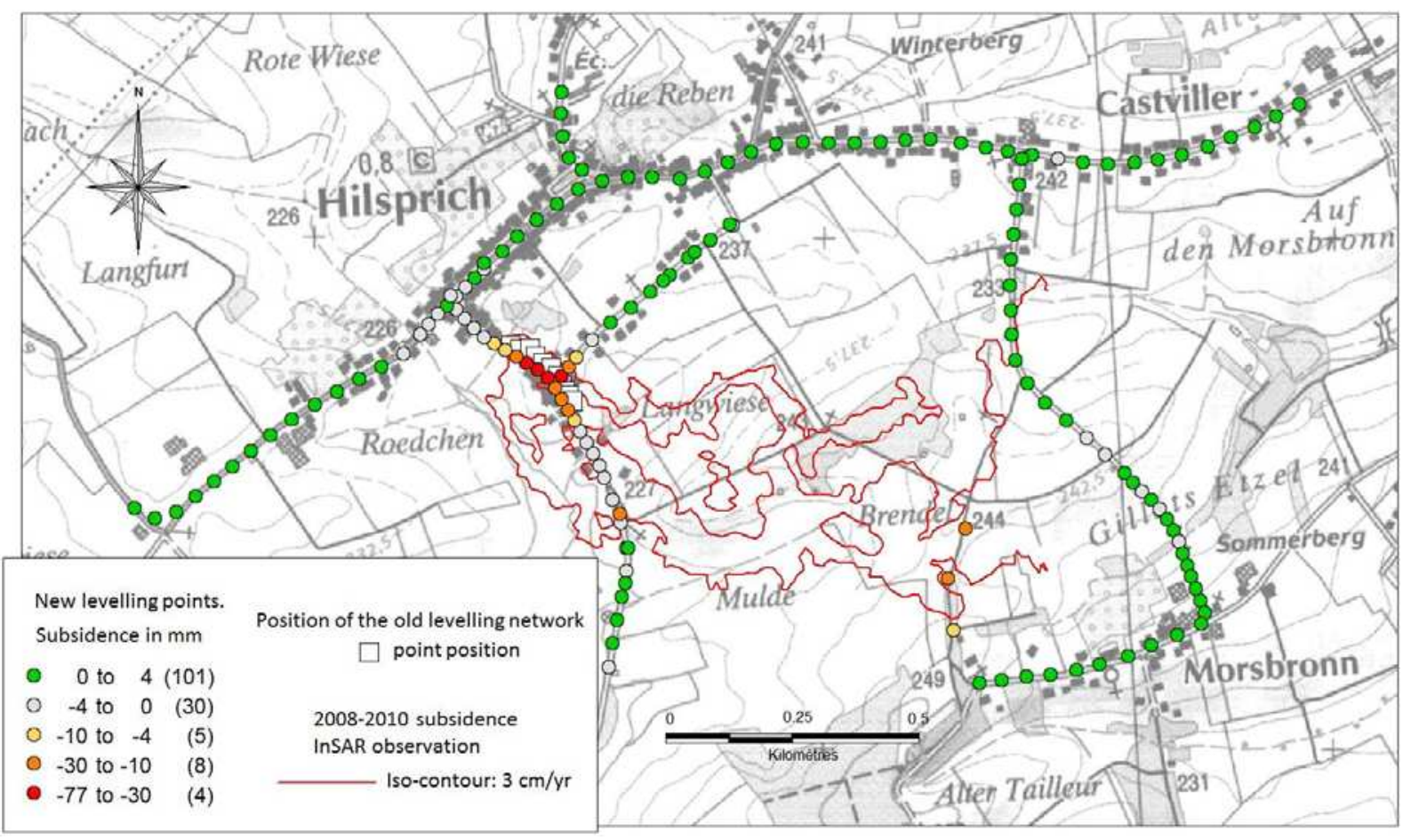




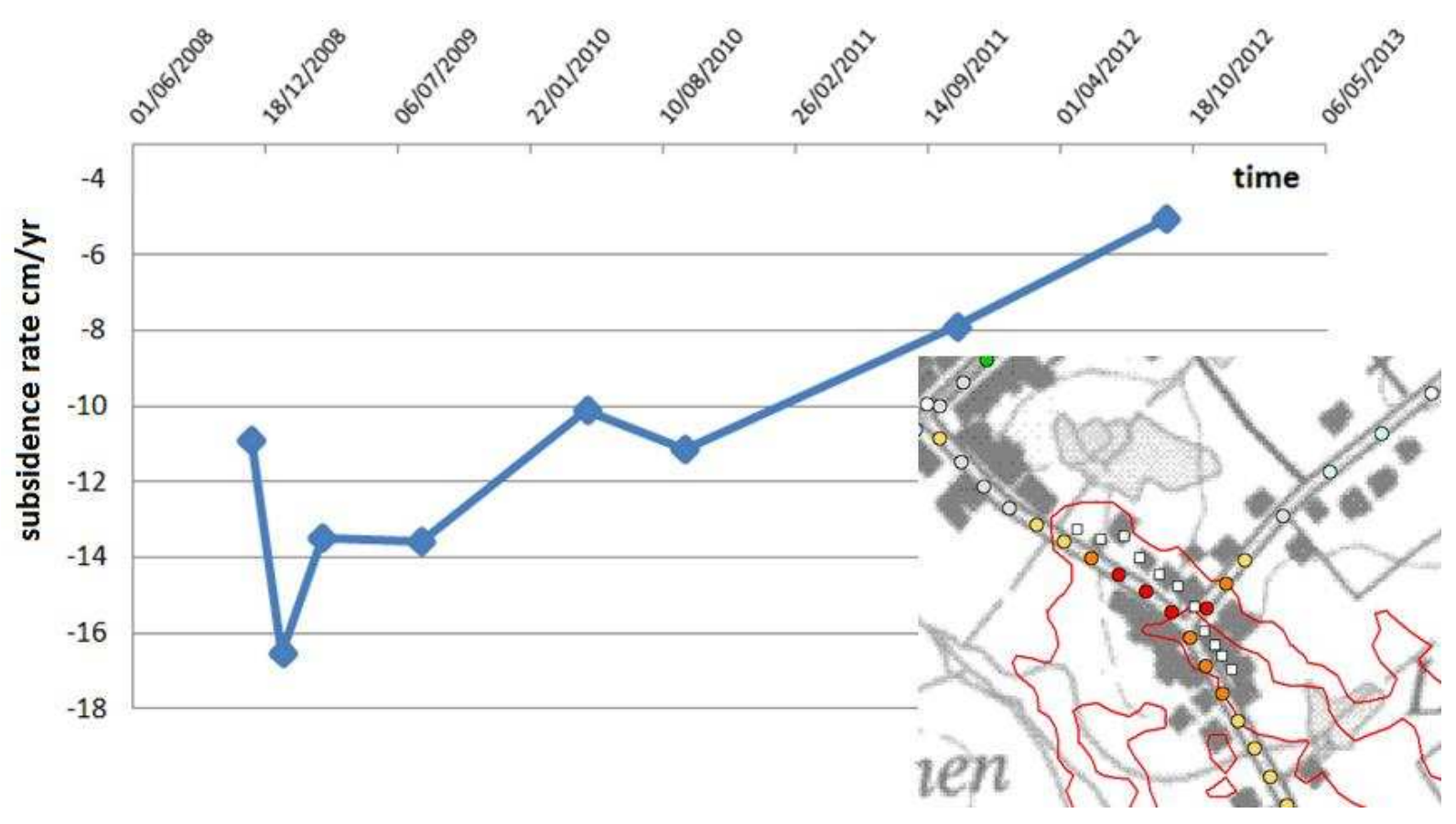

Figure 10. Average time series of nine levelling points located where indicated by the

white squares on the inset (extract from Figure 8).

\section{Discussion and Conclusion}

The present study addressed the subsidence phenomenon in Hilsprich, in which SAR interferometric techniques provided useful information. Conventional DInSAR based on PALSAR data processing for the 2008-2010 period revealed clear boundaries for the subsidence area, an elliptic bowl $1 \mathrm{~km}$ long $\times 0.3 \mathrm{~km}$ wide, and estimated the maximum subsidence rate to be about $9 \mathrm{~cm} / \mathrm{yr}$. It also seems to show a possible decrease of the rate. Application of the PSI technique using ASAR data indicated that the subsidence began to occur in June 2006.

The limitations for such an exercise were: (1) The small PALSAR dataset limited the possibility of interferogram stacking for enhancing the ratio between the deformation signal and various sources of signal degradation (atmospheric effects, etc.) (2) The temporal decorrelation of non-built-up areas required the use of short temporal baselines. Since this limited the reliability of the results for slow deformation rates, we were constrained to focus on more rapid deformation rates of several $\mathrm{cm} / \mathrm{yr}$. processing of a reduced set of ALOS/PALSAR data (eight items only) on subsidence of small lateral dimension in 
non-urban sectors, and the use of this information to install a consistent, on-site, ground-based monitoring system for optimizing the measurement networks. Electrical auscultation devices were localized on the basis of these observations and the levelling network was redefined.

Finally, it points to the applicability of future L-band missions, such as ALOS-2, that appear to be adapted to this kind of phenomenon/land-cover context. In terms of risk management related to subsidence, phenomena with similar characteristics (rate, size, environmental context) in fact occur relatively frequently.

\section{Acknowledgements:}

This study was carried out with the support of a French fund for major natural hazards prevention ("Barnier Fund"). We thank the Territory of Moselle departmental directorate for collecting this fund with the aim of hazard mapping in Hilsprich.

\section{References}

Cartannaz, C., \& Midot, D. (2011). Audit des levers topographiques sur la commune d'Hilsprich - Rapport BRGM/RP-60100large scale landslide in La Reunion Island using Differential SAR interferometry (JERS and Radarsat) and correlation of optical images (Spot 5), Sensors, 9(1):616-630. districution of SAR Permanent scatterers, Proceedings of the Fringe 2003 Workshop, Frascati: ESA (pp. 1-5) 

Monitoring residual mining subsidence of Nord/Pas-de-Calais coal basin from Differential and Persistent Scatterer Interferometry (Northern France, Journal of Applied Geophysics, 69(1):24-34 landers earthquake mapped by radar interferometry, Nature, 364:138-142 Geophysics, 36(4):441

296

Mathieu, F. (2011). Caractérisation d'un affaissement par méthodes électriques sur la commune d'Hilsprich (57) - BRGM/RP60482-FR, Orléans: BRGM

Perski, Z., \& Jura, D. (1999). ERS SAR interferometry for land subsidence detection in coal mining areas, Earth Observation Quarterly, 63:25-29 monitored by radar satellite radar interferometry, International Journal of Remote Sensing, 24(4):891 PSIC4 project results, Journal of Applied Geophysics, 68(3):335-347. 
312 Zebker, H.A, \& Villasenor, J. (1992). Decorrelation in interferometric radar echoes, IEEE Transactions on Geoscience and 313 Remote Sensing, 30:950-959. 